POLLACK PERIODICA

An International Journal for Engineering and Information Sciences

DOI: $10.1556 / 606.2017 .12 .1 .8$

Vol. 12, No. 1, pp. 93-106 (2017)

www.akademiai.com

\title{
CONSIDERATION OF TEMPERATURE AT THE MODULI OF ASPHALT LAYERS FOR A SUGGESTED MECHANISTIC OVERLAY DESIGN METHOD
}

\author{
Zoltán SOóS \\ Department of Highway and Railway Engineering, Budapest University of Technology and \\ Economics, Múegyetem rakpart 3. Hungary 1111, e-mail: soos.zoltan@epito.bme.hu
}

Received 11 September 2016; accepted 31 December 2016

\begin{abstract}
The paper addresses the determination of a stiffness-temperature correction model for the use in a mechanistic overlay design method, developed at the Department of Highway and Railway Engineering, Budapest University of Technology and Economics. Eleven models are selected and evaluated based on 215 laboratory stiffness test results at various temperatures of 47 different AC22 binder course type mixes. As the results showed, for the rough temperature correction of Hungarian binder course mixes for the use in the proposed design method; the model used by the AASHTO 1993 pavement design method is most accurate based on the standard error of the estimate of the selected models.
\end{abstract}

Keywords: Temperature correction, Asphalt stiffness, Back-calculation

\section{Introduction}

In the past decades there have been large-scale developments on the primary road network in Hungary as compared to the previous period. This sharp development of the road network is expected to lead to a change of focus from the design and construction of new roads to the maintenance, design and construction of overlays of the existing ones. The methods provided by the current standard for pavement and overlay design [1] - however once state of the art - have become outdated since their development, as they cannot consider advances in technologies and materials, thus cannot objectively compare the differences between given overlay designs. This often leads to uneconomical - over-designed - solutions at new pavement designs and overlay designs as well. As these problems have been recognized by governmental professionals, the 
work on an alternative, analytically based design method for new pavements has begun [2]. The official development of a modern overlay design guide is yet to come, despite the experiences of some previous research, indicating there is in fact a need for it. The work that originally begun within the commission of MAÚT (Hungarian Road Society) resulted in a detailed design method, being able to assess a high variety of technologies and materials currently used in Hungary [3]. Researchers at the Department of Highway and Railway Engineering, Budapest University of Technology and Economics have been focusing on overlay design for several years. Fi and Szentpéteri developed a method based on the multilayer linear elastic theory, capable to assess the mechanical properties of the existing structure and the overlay as well [4], [5]. The method presented by the author and colleagues of the current paper uses a similar approach, but offers a simpler solution, which is based on the linear elastic multilayer theory, utilizing the Method of Equivalent Thicknesses (MET). It is proposed for pavement structures that consist of a relatively thick asphalt layer with considerable remaining fatigue life and a base layer with good bearing capacity, i.e. primarily for the overlay design of highways and primary roads [6], [7]. However some solutions used in the proposed method, require further research to justify the use of bibliographic data and/or to develop new correlations valid for the Hungarian environment. The aim of the design method in question is to consider the actual material performance - stiffness, fatigue, remaining fatigue life - of the overlay and the existing pavement structure. The design process is shown in Fig. 1, where the existing pavement, as the initial state is shown by part a). The method assumes that the existing layers and the overlay will work together, resulting in the critical strain with regard to fatigue failure to be at the bottom of the total asphalt layer. Accordingly the mechanical function of the overlay will be to reduce the strains at this depth to a tolerable extent, that is, to fulfill the fatigue criterion.

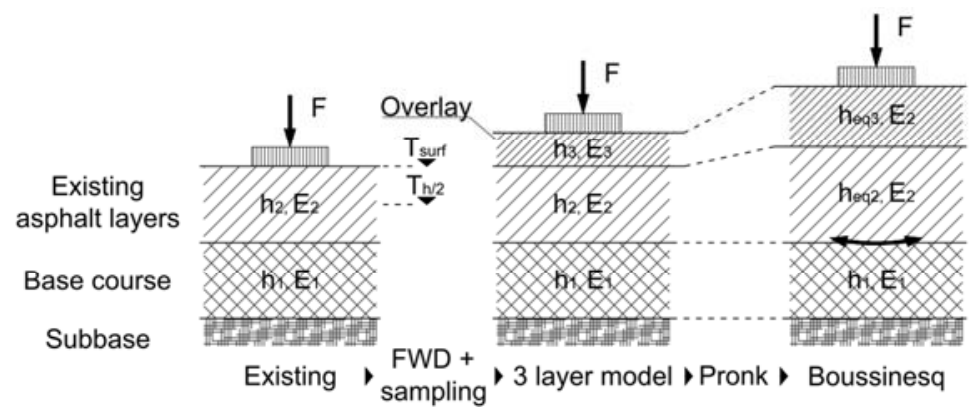

a)

b)

c)

Fig. 1. a) Existing pavement, b) 3-layer model, c) method of equivalent thicknesses

To consider the strains occurring at the bottom line of the overlaid asphalt layer and to assess various properties of given overlay technologies a three layered model is used, which consists of an infinite half-space - as a subbase -, a base layer and an asphalt layer with the overlay. The layers are defined using their thickness, stiffness and Poisson's ratio, as it is shown in Fig. 1 b. After the merging of the layers stresses and strains at arbitrary depths below a specified load can be calculated according to the Boussinesq 
equations, for various overlay technologies, enabling the verification of the fatigue criterion at the bottom line of the asphalt layer. For the calculations all layers above the base layer - existing asphalt and overlay - must be merged. To do this, amongst several available methods the one proposed by Pronk was suggested, which is based on the equivalence of the EJ bending moment of the virtual layer and the original layer, as shown by Eq. (1) [8].

$$
h_{e q}=\left[\frac{A^{4}+4 \cdot N \cdot A^{3}+6 \cdot N \cdot A^{2}+4 \cdot A \cdot N+N^{2}}{(A+1)^{3} \cdot(A+N)}\right]^{\frac{1}{3}} \cdot\left(h_{1}+h_{2}\right),
$$

where $A=h_{2} / h_{1} ; N=E_{1} / E_{2} ; h_{i}$ is the thickness of the layers (1-upper, 2-lower layer) [mm], $h_{e q}$ is the total equivalent thickness with moduli $E_{2}[\mathrm{~mm}] ; E_{i}$ is the modulus of layer $i[\mathrm{MPa}]$.

The merging of layers simplifies the original multi-layered model and results in a system as it is shown in Fig. 1c, which meets the boundary conditions of the Boussinesq equations, which may be then used to calculate stresses and strains. As Fig. 1 and Eq. (1) show, the correct determination of layer stiffness is important not only for the definition of the model, but also for the solution to be computable using MET. At the same time it is trivial, and also proven in Hungarian research, that temperature has a severe effect on the stiffness of asphalt mixes, which is determinative of the pavement life [9], [10]. This effect is primarily due to the temperature [11], [12], [13] and frequency [14], [15] performance of the bitumen used as binder. Based on various considerations, input moduli values required for modelling are suggested to be determined using back-calculation of Falling Weight Deflectograph (FWD) data. As the temperature of the asphalt layer and at given depths can be various during the measurements, the introduction of a correctional factor is required, which considers the effect of temperature on the stiffness, or measured deflection, and transforms measured values to a given reference temperature.

\section{Possibilities to consider the effects of temperature}

The equivalent temperature was chosen as reference, which is a virtual value developed for pavement design. The equivalent temperature is calculated considering various pavement temperature-traffic combinations, according to Miner's cumulative damage law. For its value, Fi and Pethö found $17.7^{\circ} \mathrm{C}$ based on Hungarian data [16]. Later Pethő extended the original research with the analysis of the temperature profile of the structures given in the Hungarian pavement catalogue, and stated that the use of $20^{\circ} \mathrm{C}$ as equivalent temperature, as according to the current standard, is adequate for design purposes [2]. The temperature of the whole asphalt layer, with a minor error for the sake of safety, will supposedly be defined by the temperature at the median of the existing asphalt layer, and accordingly the stiffness of the asphalt layer will be defined by the value valid for this temperature. 
As previously stated the input moduli are determined by back-calculation of FWD data. There are basically two options to consider temperature (and naturally, other environmental factors) during the processing of FWD data, as it is shown in Fig. 2.

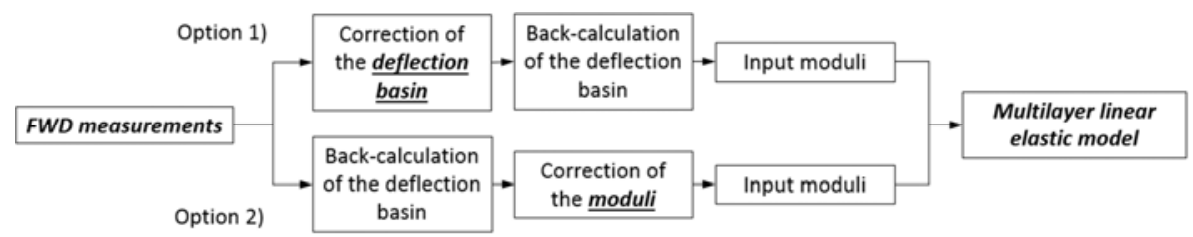

Fig. 2. Options to consider corrections at the determination of the input moduli

Option 1) is to correct the deflection basin itself that is, to correct the value of the deflections measured to a reference temperature, and use the corrected values for further calculations. This option is currently used by the Hungarian standard. The effect of temperature on asphalt layers thinner than $100 \mathrm{~mm}$ is proven to be negligible [17], while the temperature correctional factor for asphalt layers thicker than $100 \mathrm{~mm}$, to a reference temperature of $20^{\circ} \mathrm{C}$, it is shown by Eq. (2), according to the standard [1],

$$
c_{T}=1.3-0.015 \cdot T_{\text {surf }}
$$

where $c_{T}$ is the temperature correctional factor [-]; $T_{\text {surf }}$ is the temperature of the pavement surface at the time of the FWD measurement $\left[{ }^{\circ} \mathrm{C}\right]$.

It must be noted that in spite that the relevant COST 336 report suggests that temperature should be in fact measured at the median of the asphalt layer [18], in the Hungarian, similarly to most international practices only the surface temperature of the pavement is registered, although the temperature profile along depth is only partly dependent on the surface temperature [19], [20], [21], [22]. As the current Hungarian overlay design method is based on the center-of-load deflections, the correction shown in Eq. (2) cannot be used to correct the other sensors.

In the proposed design method the authors suggested the required moduli values to be determined using back-calculation of the deflection basin, and for this the correction of all sensor measurements would be required. There are several known corrections regarding the deflection basin. E.g. the research of Wagberg incorporating a representative number of FWD measurement in Sweden resulted in an empirically based correctional factor for the first $600 \mathrm{mms}$ of the deflection basin to a reference temperature of $20^{\circ} \mathrm{C}$, considering the thickness of the asphalt layer [23]. Jansen suggested correctional factors based on the temperature at $50 \mathrm{mms}$ below pavement surface, for 'high' $\left(>20^{\circ} \mathrm{C}\right)$ and 'low' $\left(<20^{\circ} \mathrm{C}\right)$ temperatures, based on temperature and the measured deflections [20]. A research conducted within the Strategic Highway Research Program (SHRP) resulted in correctional factors for 'strong' and 'weak' subbases, based on the temperature and the thickness of the asphalt layer [24]. As previously stated there is no acknowledged Hungarian method to correct the whole deflection basin, and the available international models, without proper control measurements and validation, cannot be directly used. Until the required research is 
done, in the proposed design method Option 2) is suggested in which the deflections measured under various environmental conditions are directly used for the backcalculation of the layer moduli, and corrections are carried out thereafter. This paper refers to the correction of asphalt layers' moduli. For this a stiffness-temperature model must be used, of which the most well-grounded ones are presented in Section 3.

\section{Temperature correction of the stiffness modulus}

The paper presented by García and Castro gives a comprehensive presentation of the main models developed for the temperature correction of asphalt mixes [25]. The majority of the available models correct the stiffness measured at a given temperature to a reference temperature; however some researchers developed general temperaturestiffness functions. The correctional factors presented in the following equations have been transformed to the form shown by Eq. (3),

$$
f_{\text {ref }}=\frac{E_{\text {ref }}}{E_{\text {meas }}}
$$

where $f_{\text {ref }}$ is the temperature correctional factor [-]; $E_{\text {ref }}$ is the stiffness at the reference temperature $[\mathrm{MPa}] ; E_{\text {meas }}$ is the stiffness measured at an actual temperature [MPa].

The $f_{\text {ref }}$ values calculated according to cited researches are shown in Eqs. (4)-(13):

Ullidtz \& Peattie [26],

$$
f_{\text {ref }}=\frac{1}{1-1.384 \cdot \log \left(T / T_{\text {ref }}\right)}, T_{\text {ref }}=15^{\circ} \mathrm{C},
$$

Johnson \& Baus [27],

$$
f_{r e f}=10^{-0.0002175 \cdot\left(T_{r e f}^{1.886}-T^{1.886}\right)}, T_{r e f}=15^{\circ} \mathrm{C},
$$

Baltzer \& Jansen [28],

$$
f_{r e f}=10^{-0.018 \cdot\left(T_{r e f}-T\right)}, T_{r e f}=20^{\circ} \mathrm{C},
$$

AASHTO 1993 [29],

$$
f_{\text {ref }}=\frac{10^{6.451235-0.00016467 \cdot T_{\text {ref }}{ }^{1.92544}}}{10^{6.451235-0.00016467 \cdot T_{\text {ref }}} 1.92544}, T_{r e f}=68^{\circ} \mathrm{F},
$$


Kim et al. [30],

$$
f_{r e f}=10^{-0.0153 \cdot\left(T_{r e f}-T\right)}, T_{r e f}=68^{\circ} \mathrm{F},
$$

RDO-Asphalt 09 [31],

(discrete modulus values for given temperatures),

Stubstad et al. [32],

$$
f_{r e f}=\frac{1}{1-2.2 \cdot \log \left(T / T_{r e f}\right)}, T_{r e f}=25^{\circ} \mathrm{C},
$$

Lukanen etal. [33],

$$
f_{\text {ref }}=10^{-0.0195 \cdot\left(T_{r e f}-T\right)}, T_{r e f}=20^{\circ} \mathrm{C},
$$

Chen et al. [34],

$$
f_{r e f}=\frac{\left(1.8 \cdot T_{r e f}+32\right)^{2.4462}}{(1.8 \cdot T+32)^{2.4462}}, T_{r e f}=25^{\circ} \mathrm{C},
$$

Chang et al. [35],

$$
f_{\text {ref }}=10^{-0.02822 \cdot\left(T_{r e f}-T\right)}, T_{r e f}=25^{\circ} \mathrm{C},
$$

EVERCALC [36],

$$
f_{\text {ref }}=10^{-0.000147362 \cdot\left(T_{r e f}{ }^{2}-T^{2}\right)}, T_{r e f}=77^{\circ} \mathrm{F},
$$

where $T$ is the test temperature $\left[{ }^{\circ} \mathrm{C}\right] /\left[{ }^{\circ} \mathrm{F}\right] ; T_{\text {ref }}$ is the reference temperature $\left[{ }^{\circ} \mathrm{C}\right] /\left[{ }^{\circ} \mathrm{F}\right]$.

Due to length issues of the current paper methods cannot be introduced in detail. Reference temperatures are also shown, as the presented models have been developed with the consideration of a specific reference temperature, e.g. the one used by the given country for pavement design, and were found valid only for the given condition (values in brackets are chosen for general models).

Fig. 3 shows correctional factors transformed for the reference temperature of $20^{\circ} \mathrm{C}$, i.e. $T_{r e f}=T_{e q}=20^{\circ} \mathrm{C}$, as used by the current Hungarian standard and as suggested in the 
proposed design method. On the graph the temperature interval of $+5^{\circ} \mathrm{C} \ldots+30^{\circ} \mathrm{C}$, allowed for dynamic deflections by the current Hungarian standard is also shown [37].



Fig. 3. Fref values for various methods, calculated for $\mathrm{Tref}=20^{\circ} \mathrm{C}$

As it has been shown, the values according to some methods having different original reference methods have slightly changed. The model used by EVERCALC, the RDO-Asphalt 09, the corrections developed by Johnson and Baus, and the model given by the AASHTO design guide suppose the highest stiffness reductive effect of high temperatures, whereas the other models provide a factor between 2.5-4.5 at the test temperature of $40^{\circ} \mathrm{C}$. As there is no possibility to perform a high number of laboratory tests during the development of the proposed design method, the presented models are analysed for use.

In the proposed design method the temperature of the asphalt layer, to the sake of safety, is defined by the temperature estimated - or measured - at the median of the existing asphalt layer, as it is shown on part in Fig. 1. Accordingly, the presented models are tested based on the laboratory tests of an asphalt mix typically found at this depth, AC22 binder course. Section 4 presents laboratory tests and results.

\section{Laboratory tests}

The asphalt mix first used for validation was sampled from a mixing plant, thus a good homogeneity can be assumed. Gyrator specimens were prepared for the bulk density, according to the standard [38], with $120 \mathrm{~mm}$ height and $150 \mathrm{~mm}$ diameter, from which $40 \mathrm{~mm}$ thick specimens were cut. Bulk density was repeatedly tested for the specimens. Three specimens were selected with the closest densities for further testing, with an average of $2556 \mathrm{~kg} / \mathrm{m}^{3}$, st.dev. 10.3, and spread $26 \mathrm{~kg} / \mathrm{m}^{3}$. Followed by adequate conditioning, IT-CY stiffness was tested according to MSZ EN 12697-26:2012 [39], at $0,10,20,30,40^{\circ} \mathrm{C}$, which covers the allowed temperature interval for FWD measurements. Fig. 4 shows results conducted on three specimens. 


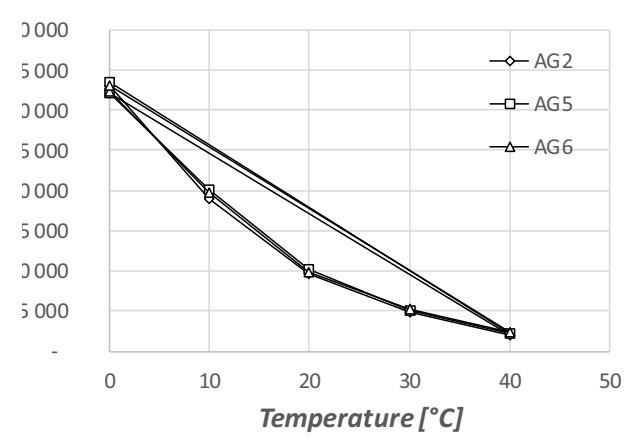

\begin{tabular}{|c|c|c|}
\hline Temperature & Stiffness & St.dev. \\
\hline$\left[{ }^{\circ} \mathrm{C}\right]$ & {$[\mathrm{MPa}]$} & {$[\%]$} \\
\hline 0.0 & 32560 & 1.7 \\
\hline 10.0 & 19695 & 3.0 \\
\hline 20.0 & 9845 & 2.7 \\
\hline 30.0 & 5051 & 3.2 \\
\hline 40.0 & 2238 & 9.5 \\
\hline 0.0 & 32912 & 1.9 \\
\hline
\end{tabular}

Fig. 4. Stiffness moduli of selected specimens at various temperatures

A control measurement was performed at $0^{\circ} \mathrm{C}$ at the end to check whether the measurement would cause permanent deformations of the specimens. As it could be seen the stiffness test resulted in low Relative Standard Deviations (RSD) at all temperatures thus the results may be accepted. The value of RSD grew with temperature, indicating that the repeatability of the test is better at low temperatures. Control test results at $0^{\circ} \mathrm{C}$ verify results shown by Pethö, stating that stiffness can be tested on multiple temperatures, and on the same specimens, and can be also repeated [40]. As there was no possibility to perform additional tests during the development of the design method, previous test results, conducted also at the Pavement Laboratory at the Department of Highway and Railway Engineering were used. Analysis presented in Section 5 are based on the IT-CY stiffness test results of 47 and 27 different AC22 binder course mix types for $0-30^{\circ} \mathrm{C}$ and $0-40^{\circ} \mathrm{C}$, respectively, altogether 215 test results have been assessed.

In his research Pethö published IT-CY stiffness test results of several asphalt mix types, tested between $-20^{\circ} \mathrm{C}$ and $+55^{\circ} \mathrm{C}$, including two binder courses mixes [2]. Tóth tested mixes having various gradations, binder types and binder contents (all conform standard) on multiple temperatures between $0-30^{\circ} \mathrm{C}$, including 18 different types of AC22 binder course mixes [41]. In her research work Ávár tested IT-CY stiffness of several mixes between $0-40^{\circ} \mathrm{C}$, of which 6 types of AC22 binder course were selected [42]. Another high volume work conducted by Szentpéteri involved IT-CY tests of 18 types of AC22 mixes, at temperatures between $0-40^{\circ} \mathrm{C}$ [43]. The test results have been collected and assessed for the validation of the presented models.

Detailed properties of the selected mixes are intentionally left out of the analysis, as the goal of the research is to give a rough, but well-founded estimation. Furthermore the mixes found in layers at the depth in question in existing pavement structures are similarly, of wide variety.

\section{Analysis of the presented models}

Based on laboratory tests the model best suitable for use in the proposed design method can be chosen. The model best suited would estimate stiffness from backcalculated FWD measurements at various test temperatures between $5-30^{\circ} \mathrm{C}$, to the 
reference temperature of $20^{\circ} \mathrm{C}$, having minimal error. Using the presented corrections, reference stiffness was estimated based on the stiffness measured at various temperatures, and accuracy was evaluated in light of the actually measured temperature. The chosen model for use in the design method is the one which has the lowest standard error of the estimate, calculated as it is shown by Eq. (14),

$$
\sum_{t=0}^{40} S E E=\sqrt{\frac{\sum_{i=1}^{N}\left(Y_{i}-Y_{i}^{\prime}\right)^{2}}{N}},
$$

where SEE is the Standard Error of the Estimate; $Y_{i}$ is the $i^{\text {th }}$ measured value; $Y_{i}^{\prime}$ is the $i^{\text {th }}$ estimated value for a given measured value; $i=1 . . N$ is the number of analyzed asphalt mixes; $t$ is the analyzed temperatures; $t=0,10,30,40^{\circ} \mathrm{C}$. Fig. 5 shows SEE values for the selected models.



Fig. 5. Sums of calculated SEE values for various methods

As it can be seen most models become sensitive at higher differences from the reference temperature, while less sensitive within the $+/-10^{\circ} \mathrm{C}$ range. The method given by Chen and colleagues [34] supposes extremely high stiffening effect to low temperatures, whereas the correction given by Ullidtz and Peattie [26] is the most balanced. The sums of the SEE values for each model are shown by the right side graph in Fig. 5. As it can be seen the most accurate model is the one used by the AASHTO 1993 design guide [29], and similar accuracy was found for the correction given by Johnson and Baus [27]; the presented SEE values are acceptable.

\section{Example of the use of the correction}

Fig. 6 shows deflection basins measured at given moments throughout a day at the same section using Dynatest FWD. Testing device was moved between measurements, to allow the pavement to heat and cool as normally. As it can be seen, there are 
significant differences between deflections measured at various parts of the day, according to the changes of temperature within the asphalt layer, as expected, primarily in the case of the sensors closer to the centre-of-load [14], [44]. The pavement structure at the section of the measurements consisted of a $19 \mathrm{~cm}$ thick asphalt layer, $20 \mathrm{~cm}$ hydraulic base and $20 \mathrm{~cm}$ granular base. To estimate the temperature at given depths within the asphalt layer, the model used by the German analytical pavement design method was previously suggested, as it is shown in Eq. (15) [31],

$$
T_{\text {mid }}=a \cdot \ln (0,01 \cdot z+1)+T_{\text {surf }},
$$

where $T_{z}$ is the asphalt temperature at depth $z\left[{ }^{\circ} \mathrm{C}\right] ; z$ is the depth below carriageway surface $[\mathrm{mm}] ; T_{\text {surf }}$ is the surface temperature $\left[{ }^{\circ} \mathrm{C}\right] ; a$ is the parameter as a function of $T_{\text {surf }}[-]$.

For purposes of the design method the temperature is to be estimated at the median of the layer, i.e. $z=9.5 \mathrm{~cm}$. $T_{\text {mid }}$ temperatures at this depth are calculated based on Eq. (15) and the temperature measured on the surface of the pavement at the time of the deflection measurements. Stiffness correctional factors $f_{\text {ref }}$ are calculated according to the AASHTO model [29], as it is shown in Eq. (7). Eventually the estimated moduli for the reference temperature $T_{r e f}=20^{\circ} \mathrm{C}$, determined using the back-calculation of the deflection basin measured at different temperatures, corrected according to the AASHTO model [29] are shown in the last column of Table I.

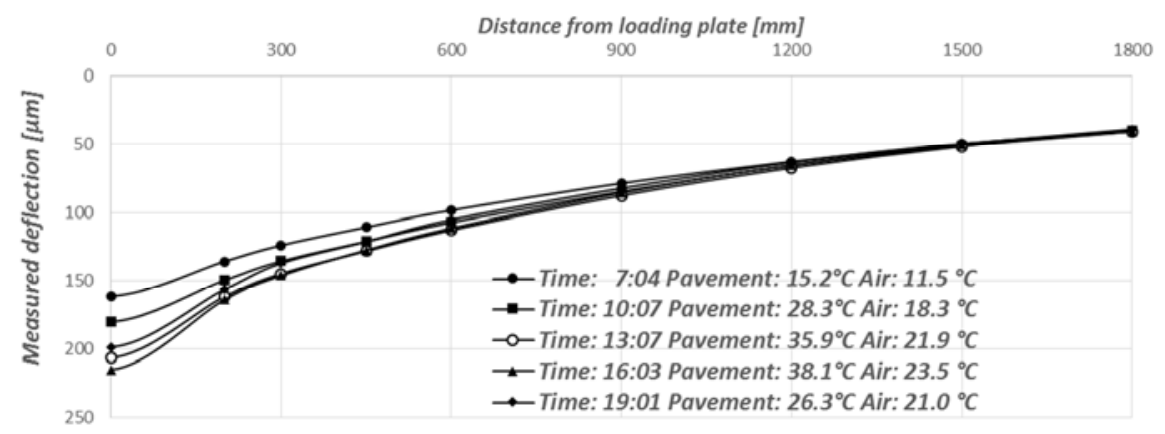

Fig. 6. Deflection basins measured at various moments in a single section

As it is shown in Table I there are considerable differences in the moduli estimated for the reference depth. As the value of correctional factor is well-grounded, this is due to the estimation of the temperature at depths within the asphalt layer, which only considers pavement surface temperature, whereas the total absorbed energy is determinative. In this field further research is to be done. However detailed data is hard to register and was not available for the current research. Altogether, moduli presented are adequate for pavement design purposes. 
Table I

Calculation of the input moduli used for overlay design

\begin{tabular}{|c|c|c|c|l|c|c|l|}
\hline Time & $\mathrm{T}_{\text {surf }}$ & 'a' & \multicolumn{2}{|c|}{$\mathrm{T}_{\text {mid }}$} & Moduli & $\mathrm{f}_{\text {ref }}$ & Input moduli \\
\hline $7: 04$ & $15.2^{\circ} \mathrm{C}$ & 0.4 & $15.5^{\circ} \mathrm{C}$ & $59.8^{\circ} \mathrm{F}$ & $5623 \mathrm{MPa}$ & 0.756 & $4253 \mathrm{MPa}$ \\
$10: 07$ & $28.3^{\circ} \mathrm{C}$ & -4.0 & $25.6^{\circ} \mathrm{C}$ & $78.1^{\circ} \mathrm{F}$ & $2461 \mathrm{MPa}$ & 1.481 & $3644 \mathrm{MPa}$ \\
$13: 07$ & $35.9^{\circ} \mathrm{C}$ & -8.5 & $30.2^{\circ} \mathrm{C}$ & $86.4^{\circ} \mathrm{F}$ & $2204 \mathrm{MPa}$ & 2.117 & $4666 \mathrm{MPa}$ \\
$16: 03$ & $38.1^{\circ} \mathrm{C}$ & -8.5 & $32.4^{\circ} \mathrm{C}$ & $90.4^{\circ} \mathrm{F}$ & $1901 \mathrm{MPa}$ & 2.542 & $4832 \mathrm{MPa}$ \\
$19: 01$ & $26.3^{\circ} \mathrm{C}$ & -4.0 & $23.6^{\circ} \mathrm{C}$ & $74.5^{\circ} \mathrm{F}$ & $2903 \mathrm{MPa}$ & 1.281 & $3717 \mathrm{MPa}$ \\
\hline
\end{tabular}

\section{Conclusions}

For the use in the overlay design method the required temperature-stiffness correctional model for asphalt mixes was determined - instead of conducting a high number of laboratory tests - based on models published in professional literature, validated mostly on previous laboratory test results on Hungarian mixes, made at the Laboratory of the Department. The selected models have been originally developed, mostly, for the correction of stiffness of asphalt mixes from arbitrary temperatures to a specific reference temperature, and with specified boundary conditions. To determine the model that best suits the design method, IT-CY test results conducted at temperatures between $0-40^{\circ} \mathrm{C}$, were assessed covering the allowed pavement temperature for FWD measurements of $+5 \ldots+30^{\circ} \mathrm{C}$. Altogether some $47 \mathrm{AC} 22$ binder course mix types, 215 laboratory tests have been assessed.

Based on test results, stiffness for the reference temperature were estimated from stiffness measured on various temperatures, using the presented models. Accuracy was evaluated by calculating the standard error of the estimate for each model. It can be stated, based on a total of 215 laboratory IT-CY stiffness tests at various temperatures, that for the use in the overlay design guide proposed by the author and colleagues, the model given by the AASHTO 1993 pavement design guide is best for use, amongst the selected models, for the temperature correction of stiffness of asphalt mixes having a nominal particle size of 20-22 $\mathrm{mm}$.

Naturally a new, Hungarian correctional model should be developed, for the best approximation of the moduli of Hungarian asphalt mixes, as further research to be done.

\section{References}

[1] e-UT 06.03.13 [ÚT 2-1.202:2005], Design of road pavement structures and overlay design with asphalt surfacings, (in Hungarian) Hungarian Standard, Hungarian Roads Society, 2005.

[2] Gribovszki Z., Igazvölgyi Z., Kalicz P., Pethő L., Kisfaludi B., Tóth C., Markó G., Soós Z., Péterfalvi J., Szentpéteri I., Primusz P., Tódor D. Study of alternative design methods and principles for the introduction of alternative methods,(in Hungarian) Research Report for the Hungarian Transport Administration (KKK), 2016. 
[3] Karoliny M. Overlay design of asphalt pavements, Summary, Útügyi Lapok, Vol. 7, paper 5, 2016.

[4] Fi I., Szentpéteri I. Mechanical-empirical overlay design method for asphalt pavements, (in Hungarian) Magyar Építöipar Vol. 64, No. 3, 2014, pp. 114-119.

[5] Fi I., Szentpéteri I. A mechanistic-empirical approach for asphalt overlay design of asphalt pavement structures, Periodica Polytechnica, Civil Engineering, Vol. 58, No. 1, 2014, pp. 55-62.

[6] Soós Z., Tóth C., Szentpéteri I., Pethő L. Advanced pavement overlay design using the general mechanistic method, Proceedings of the Second International Conference on Infrastructure Management, Assessment and Rehabilitation Techniques, Sharjah, United Arab Emirates, 8-10 March 2015, pp. 88-94.

[7] Soós Z., Igazvölgyi Z., Tóth C., Pethő L. Mechanistic asphalt overlay design method for heavy duty pavements, IV Proceedings of the Conference on Road and Rail Infrastructure, CETRA 2016, Sibenik, Croatia, 23-25 May 2016, pp. 173-179.

[8] Pronk A. C. Equivalent layer theories, (in Dutch) Internal Report TW-N-86-42, Road and Hydraulic Engineering Division, The Netherlands, 1986.

[9] Bocz P. The effect of stiffness and duration parameters to the service life of the pavement structure, Periodica Polytechnica, Civil Engineering, Vol. 53, No. 1, 2008, pp. 35-41.

[10] Pethö L. Influence of temperature distribution on the design of pavement structures, Periodica Polytechnica, Civil Engineering, Vol. 52, No. 1, 2008, pp. 45-53.

[11] Füleki P. Improving pavement performance by compact-asphalt technology, Pollack Periodica, Vol. 4, No. 3, 2009, pp. 111-120.

[12] Adorjányi K., Füleki P. Performance parameters and stress sensitivity of bitumen at high temperature, Pollack Periodica, Vol. 7, No. 2, 2012, pp. 109-116.

[13] Sachs S., Vandenbossche J. M., Li Z., Barman, M. Accounting for temperature susceptibility of asphalt stiffness when designing bonded concrete overlays of asphalt pavements, Journal of Transportation Engineering, Vol. 142, No. 10, 2016, Paper No. 04016040 .

[14] Zhang J., Liu G., Hu Z., Zhu C., Pei J., Long J. Effects of temperature and loading frequency on asphalt and filler interaction ability, Construction and Building Materials Vol. 124, 2016, pp. 1028-1037.

[15] Falchetto A. C., Turos M. I., Marasteanu M. O. Investigation on asphalt binder strength at low temperatures, Road Materials and Pavement Design Vol. 13, No. 4, 2012, pp. 804-816.

[16] Fi I., Pethő L. Calculation of the equivalent temperature of pavement structures, Periodica Polytechnica, Civil Engineering, Vol. 54, No. 2, 2008, pp. 91-96.

[17] Kubányi Z. (Ed.) Determination of temperature and seasonal correction for dynamic deflection measurements, (in Hungarian) Research Report, Közlekedéstudományi Intézet, 1996.

[18] COST 336, Use of falling weight deflectometers in pavement evaluation, Final Report 4, FWD Project Level Guide, 1999.

[19] Pszczola M., Judycki J., Rys D., Evaluation of pavement temperatures in Poland during winter conditions, Transportation Research Procedia, Vol. 14, 2016, pp. 738-747.

[20] Jansen D. Temperaturkorrektur von mit dem Falling-Weight-Deflectometer gemessenen Deflexionen auf Asphaltbefestigungen, Institut für Straßenbau und Verkehrswesen, Universität Duisburg Essen, 2009.

[21] Wang T. H., Su L. J., Zhai J. Y. A case study on diurnal and seasonal variation in pavement temperature, International Journal of Pavement Engineering, Vol. 15, No. 5, 2014, pp. 402-408.

[22] Ureczky J., Tóth C. Effect of temperature on deflections, (in Hungarian) Közúti és Mélyépítési Szemle, Vol. 58, No. 3-4, 2008, pp. 9-14. 
[23] Wagberg L. G. Development of a deflection model, (in Dutch) Väg- och Transportforskningsinstitut, Neddelande 916, The Netherlands, 2001.

[24] SHRP procedure for temperature correction of maximum deflections, Strategic Highway Research Program, Research No. SHRP-P-654, Final Report, Washington, USA, 1993.

[25] García J. A. R., Castro M. Analysis of the temperature influence on flexible pavement deflection, Construction and Building Materials, Vol. 25, No. 8, 2011, pp. 3530-3539.

[26] Ullidtz P., Peattie K. R. Programmable calculators in the assessment of overlays and maintenance strategies, Proceedings of the 5th International Conference on Structural Design of Asphalt Pavements, Delft, the Netherlands, 23-26 August 1982, pp. 671-681.

[27] Johnson A. M., Baus R. L. Alternative method for temperature correction of backcalculated equivalent pavement moduli, Transportation Research Board, Research No. 1355, 1992, pp. 75-81.

[28] Baltzer S., Jansen J. M. Temperature correction of asphalt-moduli for FWD measurements, Proceedings of the 4th International Conference on Bearing Capacity of Roads and Airfields, Minneapolis, USA, 17-21 August 1994, pp. 753-768.

[29] AASHTO Guide for Design of Pavement Structures, American Association of State Highway and Transportation Officials, Washington DC, 1993.

[30] Kim Y. R., Hibbs B. O., Lee Y. C., Temperature correction of deflections and backcalculated asphalt concrete moduli, Transportation Research Board, Research No. 1473, 1995, pp. 55-62.

[31] RDO-Asphalt 09, Guidelines for mathematical dimensioning of foundation of traffic surfaces with a course asphalt surface, (Draft version), (in German) German Standard, 2009.

[32] Stubstad R., Lukanen E., Richter C., Baltzer S. Calculation of AC layer temperatures from FWD field data, Proc. 5th International Conference on the Bearing Capacity of Roads and Airfields, Trondheim, Norway, 6-8 July 1998, pp. 919-928.

[33] Lukanen E. O., Stubstad R. N., Briggs R. Temperature predictions and adjustment factors for asphalt pavement, Publication No. FHWA-RD-98-085, Federal Highway Administration, McLean, USA, 2000.

[34] Chen D.H., Bilyeu J., Lin H. H., Murphy M. Temperature correction on falling weight deflectometer measurements, Transportation Research Board, No. 1716 pp. 30-39, 2000.

[35] Chang J. R., Lin J. D., Chung W. C., Chen D. H. Evaluating the structural strength of flexible pavements in Taiwan using the falling weight deflectometer, International Journal of Pavement Engineering, Vol. 3, No. 3, 2002, pp. 131-141.

[36] EVERSERIES User's Guide, Pavement Analysis, Computer Software and Case Studies, Washington State Department of Transport, 2005.

[37] Bearing capacity of roads, Measurement of deflection, (in Hungarian) Hungarian Standard, MSZ 2509/4, 1989.

[38] Bituminous mixtures, Test methods for hot mix asphalt, Part 6, Determination of bulk density of bituminous specimens, (in Hungarian) Hungarian Standard, MSZ EN 126976:2012, 2012.

[39] Bituminous mixtures, Test methods for hot mix asphalt, Part 26, Stiffness, (in Hungarian) Hungarian Standard, MSZ EN 12697-26:2005, 2005.

[40] Pethő L. Temperature profile in asphalt pavements and its effect on the fatigue and technological design of pavement layers, (in Hungarian) PhD. Thesis, Budapest University of Technology and Economics, 2008.

[41] Tóth C. The effect of frequency, temperature and gradation on the stiffness of asphalt mixes, (in Hungarian) PhD. Thesis, Budapest University of Technology and Economics, 2010. 
[42] Ávár V. Determination of fatigue performance of asphalt mixed based on master curves determined using reduced number of test results, (in Hungarian) BSC Diploma Work, Budapest University of Technology and Economics, 2010.

[43] Szentpéteri I., Comparison of master curves of asphalt mixes before and after aging, (in Hungarian) BSC Diploma Work, Budapest University of Technology and Economics, 2010.

[44] Ahmed M. U., Rahman A., Islam M. R., Tarefder R. A. Combined effect of asphalt concrete cross-anisotropy and temperature variation on pavement stress-strain under dynamic loading, Construction and Building Materials, Vol. 93, 2015, pp. 685-694. 